УДК 338

\title{
ВЛИЯНИЕ ПАНДЕМИИ НА МИРОВОЙ ГОСУДАРСТВЕННЫЙ ДОЛГ И ПЕРСПЕКТИВЫ ЕГО ДИНАМИКИ В БУДУЩЕМ
}

\author{
Лопатина Полина Антоновна \\ студент 2 курса магистратуры \\ финансового факультета \\ РЭУ им. Г.В. Плеханова
}

Аннотация: До наступления пандемии коронавируса рост мирового государственного долга уже был значимой проблемой многих стран. После пандемии COVID-19 потребность в государственном заимствовании выросла в разы. Правительства всех стран начали предпринимать меры по минимизации негативного влияния пандемии на мировую экономику. Но после наступления второй волны, надежды на быстрое восстановление были разрушены. В данной статье рассмотрены риски, сформированные под влиянием негативных процессов, возникших в кризисное время в виде пандемии COVID-19, а также проанализированы меры по минимизации их отрицательного влияния на долговую ситуацию в мире.

Ключевые слова: государственный долг, пандемия COVID-19, Всемирный банк, инициатива приостановки обслуживания долга, мировой ВВП.

\section{THE IMPACT OF THE PANDEMIC ON GLOBAL PUBLIC DEBT AND THE PROSPECTS FOR ITS DYNAMICS IN THE FUTURE}

\section{Lopatina Polina Antonovna}

\begin{abstract}
Before the onset of the coronavirus pandemic, the growth of global government debt was already a significant problem in many countries. After the COVID-19 pandemic, the need for government borrowing has increased significantly. Governments of all countries have begun to take measures to minimize the negative impact of the pandemic on the global economy. But after the onset of the second wave, hopes for a quick recovery were destroyed. This article examines the risks formed under the influence of negative processes that arose
\end{abstract}


during the crisis in the form of the COVID-19 pandemic, and also analyzes measures to minimize their negative impact on the debt situation in the world.

Keywords: government debt, COVID-19 pandemic, World Bank, debt service suspension initiative (DSSI), world GDP.

Пандемия коронавируса спровоцировала правительства во всем мире увеличить свои расходы для поддержания экономики. В то же время страх перед вирусом в сочетании со строгими локдаунами удерживает людей дома, приводя к резкому падению налоговых поступлений, что, в свою очередь, влияет на динамику мирового долга.

Правительства всех стран начали предпринимать меры по минимизации негативного влияния пандемии на мировую экономику. К ним можно отнести монетарные и фискальные стимулы. Но после наступления второй волны, надежды на быстрое восстановление были разрушены. Мировой ВВП в 2020 году снизился на 4,3 процента, что является самым резким снижением со времен Великой депрессии. Больше всего пострадали страны с низким и средним уровнем доходов, при этом объем производства сократился на 2,5 процентов в 2020 году.

Мировой государственный долг в конце 2018 года составлял 82\% мирового ВВП, в 2019 года - 83,5\%, что больше на 1,5 процента. Но в 2020 года после объявления Всемирной организацией здравоохранения в январе чрезвычайной ситуации мирового масштаба в виде коронавируса, мировой государственный долг уже составлял 97,6\%, что на 14,1\% больше по сравнению с предыдущим годом. Несмотря на это, показатель оказался ниже оценки, сделанной МВФ. По его словам, мировой государственный долг должен был вырасти до 101,5\% мирового ВВП.

Проанализировав рисунок 1, можно сделать вывод, что 32 страны в настоящее время имеют отношение государственного долга к ВВП более $100 \%$. Это означает, что государственный долг стран больше, чем весь годовой объем производства для их экономик. Страны, которые сильно зависят от нефти, таких как Кувейт (14\%), Россия (18\%) и Саудовская Аравия (31\%) имеют небольшой долг. Подавляющее большинство стран по всему миру лежат между этими двумя крайностями, отношение госдолга к ВВП которых находится от 50\% до 99\%. 


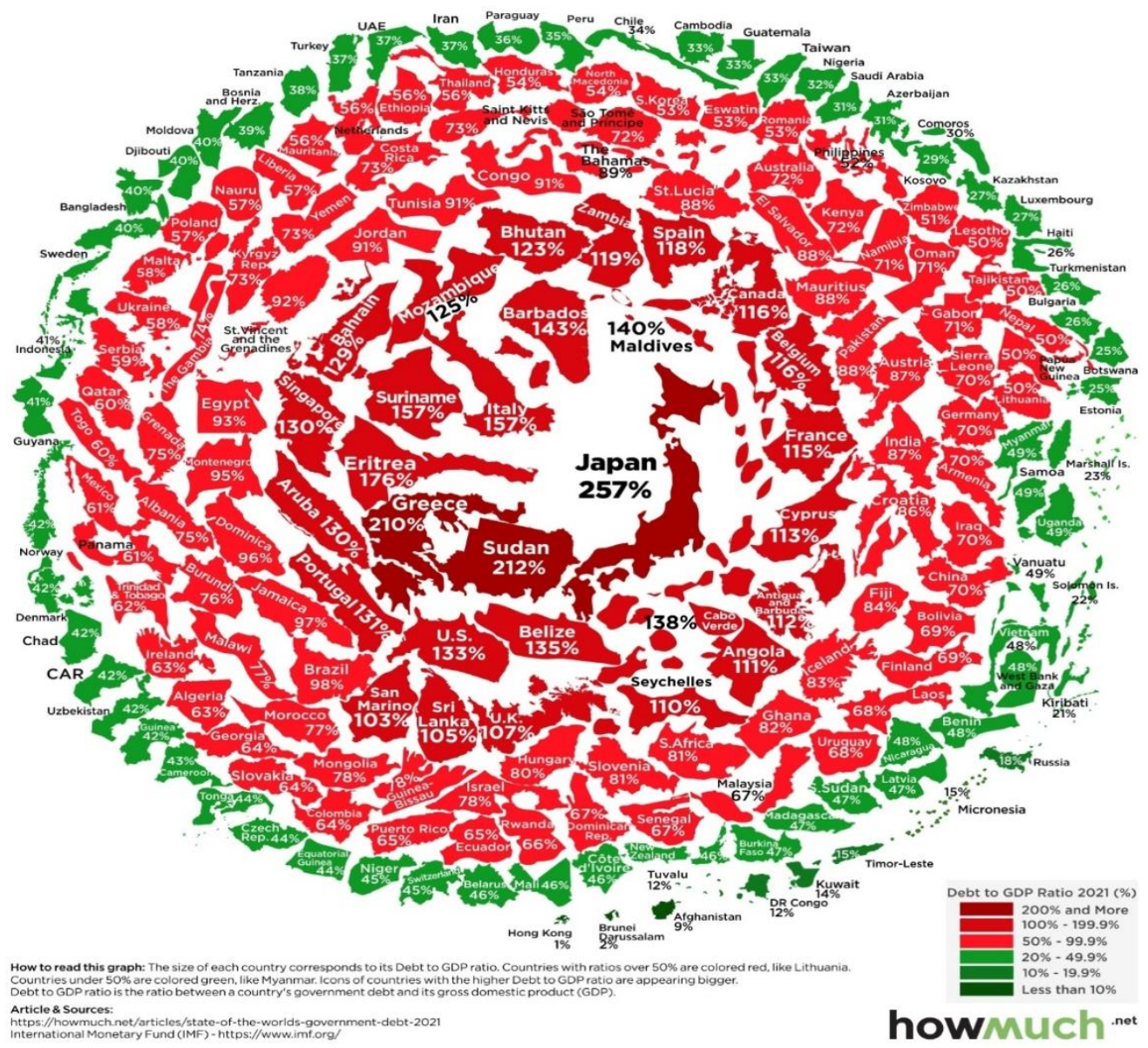

\section{Рис. 1. Состояние мирового государственного долга в 2021 году [1]}

Япония остается мировым лидером, поднявшись с 238\% ВВП до $257 \%$. Фактически, в настоящее время есть 3 страны с отношением долга к ВВП более $200 \%$, включая Грецию (210\%) и Судан (212\%). А США выросли с $129 \%$ до $133 \%$. На самом высоком уровне за последние пару лет ни одна страна не вышла из долгов, и почти везде в мире все глубже и глубже погружается в минус. Так, например, президент США Джо Байден предлагает триллионы долларов дополнительных расходов как для оживления, так и для преобразования американской экономики. Ситуация, вероятно, станет еще хуже.

По увеличению государственного долга всегда отличались США. В 2020 году он составил 129\% мирового ВВП, что на 21\% больше, чем в 2019 году. МВФ прогнозирует увеличение государственного долга в 2021 году до $133 \%$, благодаря двум пакетам финансовой помощи экономике в размерах 2,2 триллионов долларов США и 900 миллиардов США, которые были анонсированы Джо Байденом. 
Стоит отметить, что страны со средним и низким уровнем доходов пострадали по-разному. Больше всего пострадали страны Латинской Америки и страны Карибского бассейна, в отличие от стран Тихого океана и Восточной Азии. Экономическая ситуация там обстоит лучше, их производительность увеличилась на 1 процент в 2020 году благодаря Китаю.

Для Латинской Америки и стран Карибского бассейна коронавирус негативно повлиял на такие области, как здравоохранение, а также социальную и экономическую сферы, что привело к росту уровня смертности [2]. Помимо серьезной эпидемиологической ситуации в указанных странах, еще одной из основных проблем является исторически низкое доверие к государству. Правительства Латинской Америки и Карибского бассейна стараются разработать и предпринять меры по улучшению внутренней ситуации, которые смогут позволить не отступить от требований демократии, а также защитить права человека и сохранить мир внутри стран. Данные проблемы показывают, что стратегии стран имеют большие недостатки. COVID-19 показал все минусы данной модели, а также усилил проблемы неравенства, превращая трудности в острые проблемы, на которые необходимо в срочном порядке обратить внимание и разработать правильную стратегию для их решения.

Для того чтобы стимулировать улучшение экономической ситуации Экономическая комиссия для Латинской Америки и Карибского бассейна (ЭКЛАК) указала странам региона 7 направлений, на которые в краткосрочной перспективе необходимо обратить внимание для улучшения экономики:

- возобновление природных ресурсов;

- улучшение сферы туризма;

- внедрение и развитие цифровизации;

- рассмотрение промышленного здравоохранения;

- разработка электромобильности в городах;

- создание новой энергетической матрицы;

- разработка экономики замкнутого цикла.

Доля России составляет $18,6 \%$ мирового ВВП от общего объема долговой нагрузки. Целью бюджетной стратегии РФ является сохранение госдолга на низком уровне. Несмотря на это, проект федерального бюджета 2021-2023гг. предполагает увеличение отношения государственного долга к ВВП до 21,4\%. Можно сделать вывод, что Россия вернется к возвращению 
расходов бюджета к нормальному уровню в перспективе, а привлечение дополнительных денежных средств, привлеченных в ближайшие три года, поможет решить проблему с доходами граждан.

Россия стала одним из крупнейших кредиторов для стран третьего мира. Она уступила Японии, Китаю, Франции и Германии. Всемирный банк опубликовал подробный список должников России в размере 23,9 миллиардов долларов США, включающий в себя тридцать стран. Основным должником является Белоруссия, на которую приходится 9,1 миллиардов долларов США или $38,1 \%$ от всего долга третьих стран, включая долг в размере одного миллиарда долларов США, который был предоставлен в середине 2020 года. Несмотря на это, кредиты занимают маленькую часть финансовой поддержки Белоруссии [3]. По экспертной оценке, финансовая помощь Белоруссии в виде субсидий, долговых списаний, дотаций и других видов помощи составляет почти 137 миллиардов долларов США.

Третью часть государственного долга перед Россией составляют долги семи стран Южной и Юго-Восточной Азии. К ним относятся Бангладеш, Индия, Вьетнам, Камбоджа, Афганистан, Индонезия и Лаос. Также в списке должников перед Россией можно назвать такие африканские страны, как Египет, Сомали, Эфиопия, Мозамбик и Замбия. Стоит отметить, что данный государственный долг образовался во времена Советского Союза для дальнейшего расширения российского бизнеса в Африке.

В списке тридцати основных должников перед Россией можно отметить две латиноамериканские страны: Венесуэла (1,84 млрд долларов США) и Эквадор (110 млн долларов США).

За последние двадцать лет Россия простила долгов на общую сумму около 140 миллиардов долларов США таким странам, как Куба (31 миллиард долларов США), Ирак (21,5 миллиардов долларов США), Монголия и Афганистан (по 11 миллиардов долларов США), Северная Корея (10 миллиардов США) и Сирия (9,8 миллиардов долларов США) и другие страны.

Проанализировав долговые обязательства стран со средним и низким уровнем доходов, можно заметить взлеты и падения. Поддержка со стороны многочисленных институтов, включая Всемирный банк и Международный валютный фонд (МВФ), привлекли чистый приток в виде кредитов в размере почти 117 миллиардов долларов США [4]. 
Также была запущена инициатива приостановки обслуживания долга (англ. «Debt Service Suspension Initiative» - DSSI), подразумевающая предоставление странами, входящими в большую двадцатку, своих ресурсов на борьбу с пандемией. Данная инициатива вступила в силу 1 мая 2020 года. Она помогла более сорока странам получить помощь в размере свыше пяти миллиардов долларов США. 73 страны имеют право на временное приостановление платежей в обслуживании долга. Период приостановки долга установлен до декабря 2021 года, с учетом его продления при ухудшении экономической ситуации и увеличения заболеваемости в мире [5].

На рисунке 2 представлены страны, принявшие участие в программе в 2020 году. К ним относятся 66 стран, в том числе Монголия, Пакистан, страны Африки, и другие страны.

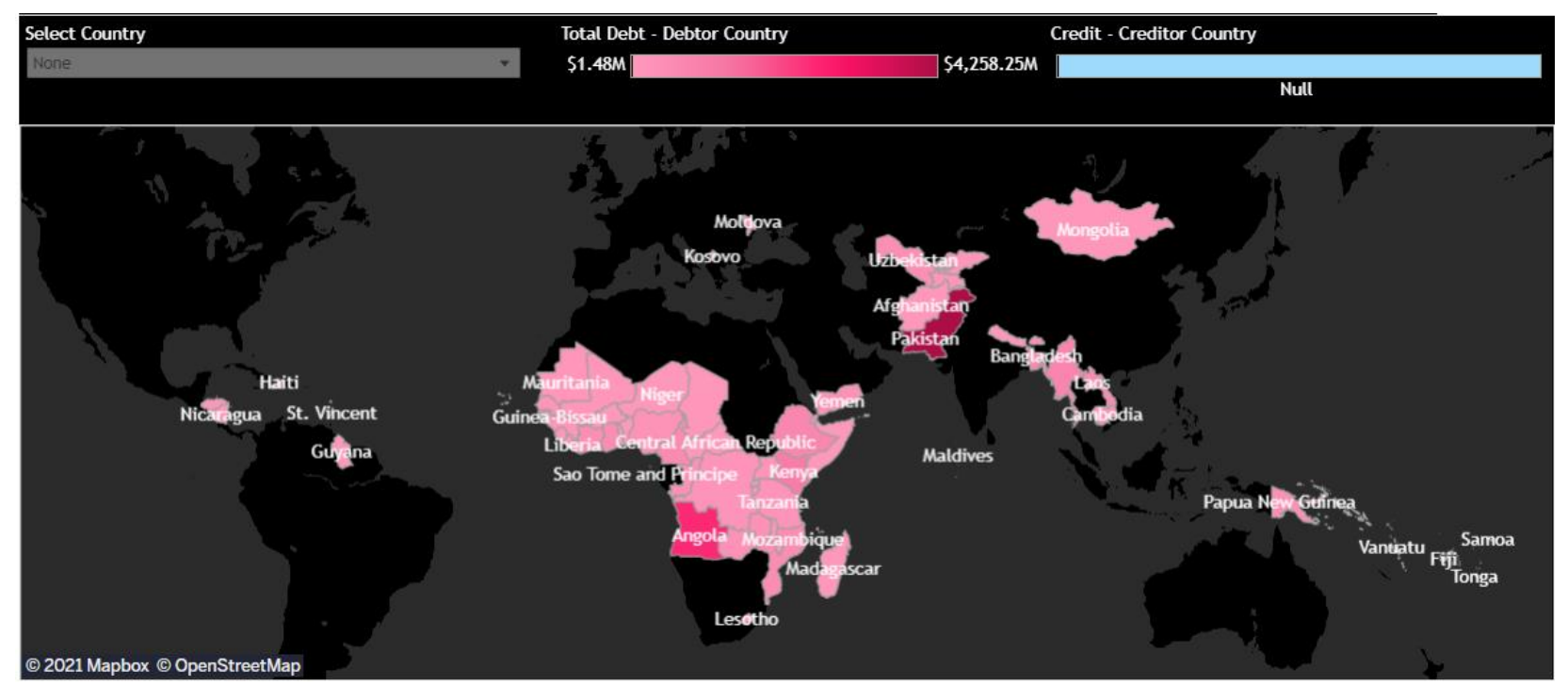

\section{Рис. 2. Состояние мирового государственного долга в 2020 году [1]}

Так, например, Афганистан приостановил возвращение долга в размере 75,4 миллионов долларов США России $(94,4 \%$ всего долга или 71,2 миллионов долларов США), Саудовской Аравии $(4,1 \%$ или 3,1 миллионов долларов США) и Кувейту (1,5\% или 1,1 миллионов долларов США).

B рамках программы DSSI Китай является одним из крупнейших кредиторов для таких стран, как Пакистан (2,92 миллиардов долларов США), Ангола (2,99 миллиардов долларов США), Кения (849 миллионов долларов США) и для других стран. Данная благотворительность является одним из 
направлений стратегии страны для дальнейшего ее развития. Китай имеет большой интерес к природным ресурсам в Анголе и в Кении. Данные страны нуждаются в экономической помощи для решения проблем, возникших с пандемией COVID-19.

США, в отличие от Китая, одолжила денег странам мира в рамках программы инициативы приостановки обслуживания долга. Одним из крупных должников США является Гана (146 миллионов долларов США).

В целом, беднейшие страны мира приостановили выплаты по суверенному долгу в размере около 17,7 миллионов долларов США в рамках программы в 2020 году.

Всемирный банк и МВФ контролируют расходы для повышения прозрачности государственного долга и обеспечения разумного заимствования нуждающимися странами. Те страны, которые воспользовались помощью большой двадцатки, обязаны использовать ресурсы улучшения медицинских, социальных и экономических секторов экономики, а также раскрывать информацию обо всех финансовых обязательствах государственного сектора, в том числе долговым инструментам и обязательствам.

Таким образом, пандемия COVID-19 негативно повлияла на динамику мирового государственного долга. Показатели долга и дефицита достигли своего исторического максимума. Средний показатель дефицита бюджета к ВВП стран с развитой экономикой достиг 9,9\% в 2021 году, а для стран с формирующимся рынком - 7,1\%, для развивающихся стран $-5,2 \%$. Учитывая то, что ситуация с коронавирусом не улучшается, и продолжают появляться новые штаммы, как выявленный в ноябре 2021 года в Ботсване и ЮАР омикрон-штамм, государственный долг будет только увеличиваться. Несмотря на это, страны с продуманной стратегией, как у Китая или у России, менее пострадают в среднесрочной перспективе, в отличие от стран Африки или Латинской Америки.

\section{Список литературы}

1. Официальный сайт How Much Understanding money [электронный pecypc] - Режим доступа. - URL: https:/howmuch.net (дата обращения: 25.11.2021). 
2. Аналитическая записка OOH. Последствия COVID-19 для Латинской Америки и Карибского бассейна. Июль 2020 года.

3. Официальный сайт Газета.ру. Плата за лояльность: кому и зачем одалживает Россия [Электронный ресурс] - Режим доступа. - URL: https://www.gazeta.ru/politics/2021/03/31_a_13541828.shtml (дата обращения: 25.11.2021).

4. International Bank for Reconstruction and Development / The World Bank. International Debt Statistics 2022, 2021.

5. Официальный сайт The World Bank [Электронный ресурс] - Режим доступа. - URL: https://www.worldbank.org/en/topic/debt/brief/covid-19-debtservice-suspension-initiative (дата обращения: 26.11.2021).

(C) П.А. Лопатина, 2021 